\title{
A IMPORTÂNCIA DO PLANEJAMENTO FINANCEIRO NA ORGANIZAÇÃO
}

\author{
Ana Paula Silva Sobrinho, Eduardo Teraóka Tofoli
}

Universidade do Oeste Paulista - UNOESTE, curso de Finanças e Controladoria, Presidente Prudente, SP. E-mail: anapaulassobrinho@gmail.com; eduardo tofoli@yahoo.com.br

\section{RESUMO}

Com as mudanças no mercado econômico, a gestão financeira desempenha um papel importante nas tomadas de decisões empresariais, na aplicação criteriosa dos recursos financeiros e, principalmente, na análise econômica e financeira da empresa. Em qualquer ramo de atividade o planejamento financeiro se faz imprescindível para que a organização tenha bons resultados, por isso, priorizar uma boa elaboração de um planejamento, é certo que menos riscos a organização terá e facilmente os objetivos traçados serão atingidos. Com isso, o objetivo desse trabalho foi de verificar a importância do planejamento financeiro para o sucesso da organização. Para atingir esse objetivo, foi realizado uma pesquisa bibliográfica, através de artigos científicos, livros e revistas sobre o assunto. Com a realização da pesquisa foi possível analisar que a elaboração correta do planejamento financeiro e sua execução permite que a empresa se mantenha no mercado e consequentemente consiga obter o sucesso empresarial, aumentando sua lucratividade.

Palavras-Chave: Gestão Financeira. Planejamento Financeiro. Elaboração Planejamento. Importância do Planejamento Financeiro. Resultados.

\section{THE IMPORTANCE OF FINANCIAL PLANNING IN THE ORGANIZATION}

\begin{abstract}
With changes in the economic market, financial management plays an important role in business decision-making, judicious application of financial resources, and especially in the economic and financial analysis of the company. In any branch of activity financial planning becomes essential for the organization to have good results, so prioritizing a good planning, it is certain that fewer risks the organization will have and easily the objectives outlined will be achieved. With this, the objective of this work was to verify the importance of financial planning for the success of an organization. To reach this goal, a bibliographical research was carried out, through scientific articles, books and magazines on the subject. With the accomplishment of the research it was possible to analyze that the correct elaboration of the financial planning and its execution allows the company to remain in the market and consequently to obtain the business success, increasing its profitability.
\end{abstract}

Keywords: Financial management. Financial planning. Elaboration Planning. Importance of Financial Planning. Results.

\section{INTRODUÇÃO}

Atualmente as organizações buscam sempre por melhores resultados, priorizando gestor financeiro e acredita-se que manter o foco é a palavra-chave para obter bons resultados do que foi planejado, pois o que se espera é que o departamento financeiro é que possa atender em tempo hábil as necessidades como liquidando suas obrigações e ainda gerando um ganho financeiro. 
Por isso, o planejamento é importante no qual todas as situações ou mudanças vivenciadas na organização faça com que o gestor precise estar ciente, para que em uma tomada de decisão outros departamentos não sejam prejudicados e o caixa da empresa também. No caso do planejamento financeiro, ele busca atingir os objetivos traçados pela empresa, oferecendo orientação para a direção, a coordenação e o controle de providências tomadas pela organização, a fim de atingir seu objetivo.

A gestão financeira desempenha um papel importante nas tomadas de decisões da empresa não somente em consiste apenas receber e pagar suas obrigações, e sim vem sendo de grande relevante no planejamento das necessidades, na inventariação dos recursos disponíveis, na obtenção de financiamentos de forma mais vantajosa, na aplicação criteriosa dos recursos financeiros e, principalmente, na análise econômica e financeira da empresa.

Cada vez mais surgem empresas e com elas também à competitividade que automaticamente pede ao mercado inovação, por isso a necessidade do planejamento na gestão financeira, pois possibilita ter controle para que a empresa não perca seu foco. Em relação à competitividade, Corrêa (2010) comenta que para as empresas alcancem o nível competitivo da economia nos dias de hoje, as mesmas precisam aperfeiçoar os recursos disponíveis a fim de alinharem-se às novas exigências do mercado. Sabendo disso, o objetivo geral deste trabalho foi de verificar a importância do planejamento financeiro para uma organização.

\section{METODOLOGIA}

Gil (2002) ressalta que a metodologia científica consiste em uma série de atividades sistemáticas e racionais para se buscar de maneira confiável, soluções para determinado problema. Ressaltam, ainda, que não há ciência sem o emprego deste tipo de modelo.

Porém, com base nos estudos realizados, para alcançar o objetivo deste artigo, essa pesquisa se caracteriza-se sendo ela descritiva, e realizado através de uma pesquisa bibliográfica em livros, artigos científicos, revistas e internet, com o intuito de coletar dados sobre o tema.

De acordo com Santos e Candeloro (2006, p. 70) a "metodologia de pesquisa bibliográfica consiste na busca de elementos para a sua investigação, em materiais impressos ou editados eletronicamente".

Para Marconi e Lakatos (1992), pesquisar é um procedimento formal com método de pensamento reflexivo que requer um tratamento científico e se constitui no caminho para se conhecer a realidade ou para descobrir verdades parciais.

\section{REFERENCIAL TEORICO}

\section{Conceito de Gestão Financeira}

Gestão financeira tem como suas funções: ter uma boa análise econômica e financeira, com aplicação criteriosa dos recursos financeiros que a organização dispõe; previsão dos recursos; análise da viabilidade econômica e financeira dos investimentos entre outras funções. Por isso, é importante ressaltar que todas as decisões que possa ser tomada em uma organização é preciso que o gestor fique ciente, para que ele possa realizar uma tomada de decisão de acordo com a real necessidade.

O administrador financeiro gerencia as informações decorrentes na organização, pois é por ele que começa todo processo de identificação, mensuração, preparação, análise e interpretação das informações que visa assegurar o uso apropriado de seus recursos. E por conta da competitividade cada vez mais frequentes entre organizações ela passou a ter conscientização da importância do gestor financeiro inserido na organização, pois passa segurança e agilidade em suas tomadas de decisões (SALOMON, 1986). 
A administração financeira tem sido de importância crescente para as empresas de pequeno e médio porte, administrador financeiro é o pilar de uma gestão, pois seu principal papel é cuidar da movimentação financeira da organização monitorando sempre seu equilíbrio ou desequilíbrio entre a entrada de dinheiro e saída do mesmo. O sucesso empresarial demanda cada vez mais o uso de praticas financeiras apropriadas. (SALOMON, 1986).

\section{Planejamento Financeiro}

Para Bodie e Merton (1999, p.416), “o planejamento financeiro é um processo dinâmico que percorre um ciclo de montagem de planos, sua implementação e revisão à luz dos resultados reais". Planejamento possibilita a elaborar plano ou cronograma, aonde se pode a aproveitar um investimento e até mesmo identificar um grau de endividamento. Gitman (2001, p. 434) comenta que "o processo de planejamento financeiro começa com planos financeiros de longo prazo ou estratégicos que por sua vez guiam a formulação de planos a curto prazo ou operacionais".

Ainda há resistência por parte do empresário, pois muitos ainda preferem fazer controle de todo os departamentos da organização sozinhos, tratando tudo por igual e sendo que não é o correto e com essa falta de experiência em planejar e não ter conhecimento dos recursos suficientes eles acabam controlando a seu modo, em outras vezes não tem o conhecimento necessário para executar tal tarefa acaba prejudicando e até mesmo impedindo o crescimento da organização. Diferente quando um empresário tem a sua frente um planejamento financeiro aonde traça diretrizes que faz a organização crescer de forma sustentável, sendo possível administrar de forma eficaz entendendo quais custos ou gastos podem ser diminuído ou cortado e também o quanto de recurso ele tem disponível (GITMAN, 2001).

Gitman (1997, p. 588) menciona que:

O planejamento financeiro é um dos aspectos importantes para funcionamento e sustentação de uma empresa, pois fornece roteiros para dirigir, coordenar e controlar suas ações na consecução de seus objetivos. Dois aspectos-chave do planejamento financeiro são o planejamento de caixa e de lucros. O primeiro envolve o planejamento do orçamento de caixa da empresa; por sua vez, o planejamento de lucros é normalmente realizado por meio de demonstrativos financeiros projetados, os quais são úteis para fins de planejamento financeiro interno, como também comumente exigidos pelos credores atuais e futuros.

Para Braga (1992, p. 230), “o planejamento financeiro compreende a programação avançada de todos os planos da administração financeira e a integração e a coordenação desses planos com os planos operacionais de todas as áreas da empresa".

\section{Ferramenta de Apoio}

As organizações têm um desafio que é buscar através das ferramentas um planejamento que dê certo e atinja sucesso. As ferramentas acabam que sendo uma aliada para uma tomada de decisão, possibilitando realizar certos negócios com um mínimo de chances de erros. Em destaque podemos considerar uma ferramenta importante o fluxo de caixa, que possibilita uma visão geral do que é realizado na organização.

\section{Fluxo de Caixa}

O principal objetivo do fluxo de caixa é possuir uma visão geral das entradas e saídas dos recursos financeiros, uma ferramenta que permite monitorar toda movimentação financeira na empresa, seja ela em acontecimento do hoje, ou uma projeção para o futuro, pois permite saber 
onde está sendo empregados os recursos e também ter o controle de gastos, mas para que tudo de certo é necessário analisar e fazer o planejamento de acordo com as necessidades.

É de suma importância para continuidade da empresa, já que é com o caixa que ela liquida suas necessidades financeiras (TELLES, 1997). O fluxo de caixa possibilita verificar se em uma tomada de decisão urgente como a empresa vai reagir na saúde financeira, se trabalhará com folga ou aperto, por isso que se faz necessário o controle diário do fluxo para que possa ter precisão das informações de entrada e saídas.

A organização deve ter um controle no fluxo de caixa sendo ele por meio de um sistema, ou até mesmo uma planilha em Excel, pois ajudará muito o empresário em tomadas de decisões, mas também é necessário que esse fluxo esteja sempre atualizado, para que em uma tomada de decisão ele possa verificar se a organização está trabalhando com folga ou aperto financeiro no período desejado. Assim então fluxo nos dias atuais é uma aliado importante ao gestor, pois está ligado ao planejamento da organização passando a ser uma etapa muito importante do planejamento estratégico.

Segundo Zdanowicz (2000, p. 173), " o controle do fluxo de caixa é tão essencial à empresa como seu processo de planejamento, pois um depende de outro para que ambos possam ser úteis e práticos."

\section{Vantagens do planejamento financeiro}

A organização que aplica o planejamento na mesma ela consegue alcançar facilmente seus objetivos, como tal seu próprio crescimento. Planejamento proporciona tomar rumo a ações estabelecendo coordenações nos processos a desenvolver, também é necessário para que não mude a direção o mesmo precisa que seja acompanhado e controlado e se necessário poderá sofrer alterações para que alcance o objetivo com sucesso.

Uma das vantagens de um planejamento financeiro é a forma de redução de custos ou desperdício que transmite certa segurança, pois acompanhar este processo pode ter todo controle dos acontecimentos na organização.

\section{DISCUSSÃO}

Planejar é uma das atividades importante da vida pessoal quanto com a vida profissional, por isso uma tomada de decisão para ser realizada sendo ela de imediato, é preciso que a empresa tenha certeza do será realizado, para que tudo dê certo. Sendo assim é necessário ter um planejamento, pois possibilita-se que até mesmo uma simples tarefa que seja realizada possa ter menor chances de falhas possíveis.

As organizações estão vivendo em um cenário de mercado de muitas incertezas e ao mesmo tempo com variedades e competitividades, e é normal que as organizações pensam em inovações. Mas muitos não sabem que planejar é necessário, e com um fluxo de caixa aonde a organização possa confiar nos dados que ali consta ficará mais fácil de alcançar os objetivos traçados. Por outro lado, se não houver esse controle para ter a ciência aonde começar e até aonde pode chegar, poderá ter um resultado de fracasso e acabar abrindo falência.

Por isso, o gestor financeiro deve priorizar um fluxo de caixa em qualquer tipo ou ramo de organização, pois somente assim a empresa poderá enxergar se há escassez ou excedente do caixa.

E é assim que hoje a organização precisa acreditar na importância de um Gestor financeiro para a mesma, mesmo tratando-se de uma organização de pequeno ou grande porte, por isso a organização tem que visar o planejamento financeiro como um elemento essencial para crescimento alcançando o sucesso empresarial. A importância de um planejamento financeiro na 
organização está relacionada ao sucesso que a mesma almeja, pode-se dizer que o planejamento é uma continuação da organização, pois sem planejar fica difícil de tomar decisões corretas.

De acordo com Maximiano (2007), o processo de planejamento é a ferramenta para administrar as relações com o futuro. O planejamento é um processo de interação da empresa com seu ambiente podendo identificar sua potencialidade orientando quais seus recursos disponíveis. A falta de planejamento é encarada como a falta de organizar o ambiente e isso acaba que levando a falência, pois se não tem o controle do que é realizado, chega a um ponto que tudo vai acontecer como consequências do que não teve previsão.

Montana e Charnov (2006), dizem que a organização tem que ser vista como a administração de nossa própria vida ou família, pois se não houver cuidado tudo foge do controle e o que foi alcançado não fará mais parte do dia a dia.

\section{CONSIDERAÇÕES FINAIS}

Com a pesquisa percebe-se que a gestão financeira é considerada como uns dos maiores setores que precisa ser bem cuidada, pois se não houver um planejamento com um fluxo de caixa bem estruturado, a organização não terá chances de crescimento em um mercado tão competitivo.

E com um cenário de mercado com tanta competitividade as empresas sempre pensam em fazer inovações, mas muitos não sabem ter um controle da aonde começar e até aonde pode chegar, e com isso acaba abrindo falência. Por isso, o gestor financeiro deve priorizar um fluxo de caixa em qualquer tipo ou ramo de organização, pois somente assim a empresa poderá enxergar se há escassez ou excedente do caixa.

Enfim, conclui-se que, hoje, a organização que planeja tem mais chance de sobreviver no mercado, no momento em que do início e a prioriza juntamente com a colaboração de todos na organização, começa a ver resultados positivos que aplicação de uma boa gestão trás para ela. Pois não tem como pensar em algo que financeiramente não há ligação, então é fundamental ter essa orientação que é muito importante em um futuro sendo ele distante ou não. É possível enxergar que hoje a empresa precisa acreditar na importância de um Gestor financeiro para a mesma, mesmo tratando- se de uma organização de pequeno ou grande porte, por isso a organização tem que visar o planejamento financeiro como um elemento essencial para crescimento alcançando o sucesso empresarial.

Com isso, o objetivo deste trabalho foi atingido, pois verificou-se a importância do planejamento financeiro para uma organização. As organizações precisam sempre estar em busca constante de informações, conhecimento, tecnologias para que então ela supere todas as empresas concorrentes, pois não precisa o empresário pensar em ter somente um empreendimento e não cuidar para que ele cresça, pensando assim é preciso que ele conheça as regras e a própria administração da organização.

\section{REFERÊNCIAS BIBLIOGRÁFICAS}

BRAGA, Roberto. Fundamentos e Técnicas de Administração Financeira. São Paulo: Atlas, 1995.

BRAGA, Roberto. Fundamentos e técnicas de administração financeira.

São Paulo: Atlas, 1992.

BODIE, Zvi; MERTON, Robert C. Finanças. Porto Alegre: Bookman, 1999. Tradução de: James Sudelland Cook. 
CANDELORO, R. J.; SANTOS, V. D. Trabalhos Acadêmicos: uma orientação para pesquisa e normas técnicas. Porto Alegre: AGE, 2006.

CORRÊA, L. Paulo França. O Uso Da Contabilidade Gerencial Como Ferramenta De Gestão Nas Pequenas E Médias Empresas Da Região Da AMREC. 2010. 91f. Trabalho de Conclusão de Curso Universidade do Extremo Sul Catarinense, Criciúma, 2010.

GITMAN, Lawrence J. Princípios de Administração Financeira - Essencial. 2. ed. Porto Alegre: Bookman, 2001.

GITMAN, Lawrence J. Princípios da administração financeira. São Paulo:

Habra, 1997.

MAXIMIANO, A. C. A. Fundamentos de administração: manual compacto para as disciplinas TGA e introdução à administração. 2. ed. São Paulo: Atlas, 2007.

MARCONI, M. A.; LAKATOS, E. M. Metodologia do trabalho científico. 4a ed. São Paulo: Atlas, 1992.

MONTANA, Patrick J. CHARNOV, Bruce H. Administração. 2. Ed. São Paulo: Saraiva, 2006.

SOLOMON, Steven. A grande importância da pequena empresa. Rio de Janeiro: Editora Nórdica, 1986.

TELES, Egberto Lucena. A demonstração de fluxo de caixa como forma de enriquecimento das demonstrações contábeis exigidas por lei. Revista Brasileira de Contabilidade. v. 26, n. 105, p.6471,1997

ZDANOWICZ, José E. Planejamento financeiro e orçamento. Porto Alegre: Sagra DC Luzzatto, 1995.

ZDANOWICZ, José E. Fluxo de Caixa. Uma decisão de planejamento e controle financeiro. 8o edição. Porto Alegre. Sagra Luzzatto, 2000.

YIN, R. K. Estudo de caso: planejamento e método. Porto Alegre: Bookman, 2005. 